\title{
Management Process of Health Promoting Hospital in a Private Hospital, Lamongan, East Java
}

\author{
Badra Al Aufa* \\ ${ }^{1}$ Hospital Administration Program, Vocational Education Program, \\ Universitas Indonesia \\ *E-mail: badraalaufa@ vokasi.ui.ac.id
}

\begin{abstract}
Background: Health promoting hospitals (HPH) need to be well-managed to generate good quality program activities. This study was conducted to explore this in depth, and a comprehensive description of the process and problems found in the management of HPH at a private hospital in Lamongan, East Java. Method: This study used the qualitative method. Data collection was conducted through semi-structured interviews, focus group discussion (FGD), observation, and document analysis. This research focused on organizational activities such as planning, organizing, actuating, evaluation and also the output of HPH. Result: In the management process, there has been no planning of HPH activities in the last three years. Organization of the HPH team is set out by Director's decree, including team roles, functions and structure of the team. However, most of the functionaries did not know that they are part of HPH unit. Many kinds of HPH activities have been conducted, such as interactive health talks on the radio, providing a health channel on television installed in some strategic places, spreading health information via posters, leaflets, banners, and also an empowering patients club. Unfortunately, the hospital top management has never evaluated the process to measure the unit's outputs. Conclusion: Overall, the main problem in the management process of HPH is a lack of commitment to performing planning activity. This happened due to low coordination among HPH team members that consisted of hospital department representatives.
\end{abstract}

Keywords: health promotion hospital, qualitative study, management process

\section{Introduction}

The Ottawa Charter for Health Promotion has been known as a First International Conference on Health Promotion and called for action to achieve Health for All (Potvin \& Jones, 2011). Health promotion is defined as the process of enabling people to increase control over, and to improve, their health (2). The Charter was included ideas to develop health promotion activities based on several settings that included cities, villages, schools, workplaces, and hospitals (Johnson \& Baum, 2001). One of the significant ideas in the Ottawa Charter was to reorient the function of health service to move in a health promotion direction (Pelikan et al., 2001).

Following the Ottawa Charter, the Health Promoting Hospital (HPH) initiative was launched in the Budapest Declaration of Health Promoting Hospitals in 1991 (Whitehead, 2004). In the document from the WHO Regional Office for Europe, HPH is described as an organization that aims to improve health gain for its stakeholders by developing structures, cultures, decisions, and processes (WHO, 2007). HPH concepts put hospitals to work on health promotion activities related to improving the quality of care, particularly for patients with chronic diseases and long-term conditions (Groene, 2006).

The WHO puts forward five standards for implementation of health promotion in the hospital which ranged over management policy, patient assessment, patient information, and intervention, promoting a healthy workplace and continuity and cooperation (WHO, 2004). Currently, after passing several phases of development, health-promoting hospitals are in the phase of restructuring, globalizing and extending the international network, and as of 2011, HPH consists of 39 networks in 26 countries on 5 continents (Pelikan et al., 2011).

Research regarding the implementation of the health promoting hospital has also grown and has been studied in several hospitals in several countries. A literature review article published in 2011 summarized several papers regarding the implementation of health promoting hospitals from Estonia, China, Scotland, Europe, Greece, England and Australia, that have been published. The paper identified seven themes which are: health-promoting hospital standards and frameworks, quality assurance, organizational support, HPH skills and training, resources, patient information and partnerships (McHugh et al., 2010). Other research regarding the implementation of health promoting hospitals has been conducted in Taiwan, which found that most HPH Network members perceived the change in organizational capacity taking place in ways such as re-aligning strategies and providing more resources for health promotion (Lee at al., 2013). Another study regarding health promoting hospitals' implementation was conducted in Iran. The research identified the implementation of health promotion in 38 hospitals based on five standards: management policy, patient assessment, patient 
information, and intervention, promoting a healthy workplace and continuity and cooperation, where the result showed that private hospitals performed better than public hospitals (Yaghoubi \& Javadi, 2013).

In Indonesia, the implementation of the health promotion hospital framework has been somewhat slower than in Europe and other countries. In 2012, the Ministry of Health of Indonesia issued a regulation regarding a technical guide for implementing health promoting hospitals (Larasanti, 2017). Research on Airlangga University Hospital, Indonesia stated that the hospital had implemented health promotion both inside and outside the building (Nurdiana, 2017). Further research, conducted on Haji Public Hospital, Surabaya, assessed the implementation of a health promotion hospital based on the regulation issued by the Ministry of Health of Indonesia, which stated that the implementation of HPH in the hospital was not fully optimized (Larasanti, 2017). Although several studies regarding HPH have been conducted in Indonesia, there is still a lack of evidence regarding the implementation of HPH and its management. This study focused on the management process of health promotion hospital implementation in one private hospital in Lamongan City, Indonesia.

\section{Method}

The research used the qualitative method. Data were collected by conducting an in-depth interview, document analysis, observation and focus group discussion. Data collection was carried out from September 2015 until January 2016. Respondents were chosen by purposive sampling method whereby informants are selected as the person best placed to answer meaningfully and thus progress the research. Therefore, the 14 informants chosen from the hospital were the Head of the Health Promotion Unit and Staff, Hospital Director, Head of the General Affairs Unit, Head of the Human Resources Unit, and Head of the Finance Unit. Moreover, we also conducted focus group discussions with the patients of the hospital to gather more information regarding implementation of HPH from another perspective. Six patients were chosen for this element of the research process.

Variables of the research are adopted by the function of management which encompass planning, organizing, actuating, controlling and evaluating. Furthermore, the function was contextualized with the aim of the research, which is to look at implementation or management of the HPH. Instruments of the research consist of open-ended questions for the interview and focus group discussion, and an observation checklist. The questions in the research instrument were designed to address the variables of the research and adapted from the Guideline of HPH Implementation issued by the Ministry of Health of Indonesia. Data analysis using thematic content analysis method was conducted manually. The first, interview process, by acquiring permission from the interviewee, was recorded with the voice recorder. After that, the researcher made an interview transcript based on the recording, then data were identified and analyzed and the researcher reported on patterns of the data.

\section{Results and Discussion}

\subsection{Results}

Respondent characteristics

Informants involved in the research are nine males and five females and from various educational settings, with both health and non-health backgrounds. The educational stage ranges from diploma to postgraduate (Master). Informant ages range from 24 to 49 years old. Table 2 shows that all of FGD participants are female. Most of the patients are housewives, with an age range of 35-62 years old. The educational level attained by FGD participants is mostly senior high school. 
Table 1. Research Informants from Hospital Unit

\begin{tabular}{lcccc}
\hline \multicolumn{1}{c}{ Position } & $\begin{array}{c}\text { Age } \\
\text { (years } \\
\text { old) }\end{array}$ & $\begin{array}{c}\text { Length } \\
\text { of } \\
\text { work } \\
\text { (years) }\end{array}$ & Gender & Educational Background \\
\hline Head of HPH Unit & 30 & 2 & Male & Medical \\
HPH unit member & 37 & 3 & Female & Public Health \\
HPH unit member & 34 & 2 & Female & Master of Pharmacy \\
HPH unit member & 40 & 4 & Male & Nurse Profession \\
HPH unit member & 33 & 10 & Male & Physiotherapy \\
HPH unit member & 24 & 1,5 & Female & Bachelor of Nutrition \\
HPH unit member & 49 & 25 & Male & Internal medicine \\
HPH unit member & 42 & 3 & Female & Bachelor of Nursing \\
HPH unit member & 41 & 2 & Male & Art and religion \\
HPH unit member & 33 & 2 & Male & $\begin{array}{c}\text { Medical Record } \\
\text { Director }\end{array}$ \\
Head of Finance & 43 & 2 & Male & Hospital Administration \\
Unit & & n/a & Female & Economic \\
Head of General & 42 & n/a & Male & Religion \\
Affairs Unit & & & & Economic \\
Head of Human & 39 & n/a & Male & \\
Resouce Unit & & & & \\
\hline
\end{tabular}

Table 2. Respondents on Focus Group Discussion (FGD)

\begin{tabular}{lccc}
\hline \multicolumn{1}{c}{ Job } & $\begin{array}{c}\text { Age (years } \\
\text { old) }\end{array}$ & Educational Background & Gender \\
\hline Housewife & 43 & Senior High School & Female \\
Civil Servant & 45 & Bachelor & Female \\
Housewife & 62 & Senior High School & Female \\
Contract employee & 47 & Senior High School & Female \\
Housewife & 61 & Senior High School & Female \\
Contract employee & 35 & Bachelor & Female \\
\hline
\end{tabular}

\section{Management of the Health Promotion Program in Hospital}

From the planning aspect, in 2015, according to a Hospital General Director decree, HPH unit members were newly formed. According to information gleaned during the interviews, a general meeting to make planning decisions among the unit members had not been conducted. Therefore, from 2014 to 2015 no planning activity was executed. Based on the interview result, no meeting was conducted because of time and schedule restrictions among staff. Moreover, one informant also said that health promotion activity had been the activity of every unit, so there was no need to draw up a specific action plan. Besides that, one informant also said that one of the problems that led to no planned activity in the HPH unit was most HPH unit members did not know that they have been chosen to work as a HPH unit member. That situation arose due to a lack of coordination among the staff of the hospital. With that condition, informants suggest that there is a need to call a meeting to create health promotion program planning. Moreover, because there is no program planning for the health promotion program, no strategies, targets, or programs have been documented. Although there is no planning for a health promotion program, some health promotion activities have been implemented as arranged by previous planning activity.

In the organizing aspect, based on the interview with the informant, the HPH unit has been formed according to a Director Decision Letter. The informant said that the HPH unit is the unit that has been assigned to implement health promotion as one of the services in the hospital that can contribute to satisfying hospital consumers. The main tasks and functions of the HPH unit and members have been described in the General Director letter.

\section{Implementation of the Health Promotion Program}

In the implementation aspect, some informants said that health promotion activities in the hospital had been conducted for a long time, since the establishment of the hospital, even though the HPH unit was only 
formed in 2013. Health promotion activities are conducted both on the inside and outside of the hospital; these include publishing health information by using leaflets, posters, and banners and giving health information directly to the patients. Beyond that, health promotion was also conducted by having a health talk session, broadcast by one of the private radio stations in Lamongan City. By way of that event, not only patients who come to the hospital can have health education, but also the wider citizenry of Lamongan city and beyond can benefit from health education.

Table 3. The theme of Management of Health Promotion Program

\begin{tabular}{lc}
\hline \multicolumn{1}{c}{ Theme and subtheme } & Selected quotes \\
\hline Planning of HPH & "We have a guide (for health promotion), but if \\
Planning activity has not been & $\begin{array}{l}\text { planning program, we do not have it because we } \\
\text { conducted }\end{array}$
\end{tabular}

Lack of coordination

\section{Organization of HPH}

HPH unit has been established

\section{Actuation of HPH}

Health promotion activities inside a building

Health promotion activities outside the building

Language used in health education sometimes is not understandable.

\section{Evaluation of HPH}

Evaluation has not been conducted Lack of planning activity

\section{"Hospital staff did not know that they are a member of HPH Unit. It is because of lack of coordination."}

\author{
"An HPH Unit has been established that \\ consists of a chairman, vice chairman, secretary \\ and member. the member comes from some \\ other unit such as nutrition, pharmacy, and \\ other units."
}
"We implemented health education on leaflets banner, radio broadcast and having a Diabetes group."
"Sometimes there is a language that I could not understand."
"There is no evaluation program; it is because there is no coordination, for the conclusion we (HPH unit) have not yet having a meeting."

Other informants also said that health education for the patient had been given by a medical doctor in both outpatient and inpatient clinics. Not only a medical doctor, but also a nutritionist, nurse, and pharmacist give health education to the patient, depending on the problem. Besides these activities, other health education given to the patient was delivered on health videos on the television in the patients' waiting room. Therefore, patients and visitors can see health messages in the waiting room of the hospital.

The hospital also has a Diabetes Patient Club for patients with diabetes who regularly come to the hospital. One of the programs for the club is a meeting every three months where not only patients were invited, but also their family, academician, and the general public. In the meeting, there is a health education session particularly about diabetes symptoms and how to prevent them. Health promotion is also conducted outside hospital building by giving health education at charity events, a healthy school program, weekend fun (Minggu Ceria) and home care.

In the FGD session, patients said that information from health education delivered by hospital staff was good enough for increasing health knowledge. One informant said the only problem of the program was that sometimes the regular speaker of the health promotion program was unable to attend, so the HPH unit brought in another speaker. Although most informants said that health education was delivered well, one informant said that sometimes she did not understand what the speaker said in the health promotion program, because the language used by the speaker was sometimes difficult to understand.

For the evaluation phase, no evaluation activity has been conducted to evaluate the health promotion program in the hospital. This is because no activity planning had been implemented so no indicators have been set. 


\section{Discussion}

The result of the research has been summarised in Table 3, which shows that there is still a lack of coordination among HPH Unit members that caused a lack of planning and no evaluating of activity, even though health promotion activities have been run in various activities. Planning and other functions of management in the health promotion program in the hospital are an important element to create a successful program.

As described by the WHO in the standard for health promotion in hospitals, on standard 1, the hospital should have a written policy for health promotion implemented as a part of the organization's overall quality improvement system (WHO, 2004). The standard emphasizes that the hospital should ensure the available resources needed in the implementation and evaluation of health promotion.

As described in the results, there is a lack of coordination among staff because program planning has not been executed. Lee, in his paper, also stated that making strong coordination in implementing health promotion in a hospital is still a challenge. Coordination in implementing health promotion in the hospital is a significant factor since it has been realized that health promotion relies on multidisciplinary work (Lee et al., 2013).

Although health promotion activities have been implemented in various activities, no health promotion program has been addressed for hospital staff. However, research conducted in Taiwan showed that health promotion programs provided by hospitals were associated with good health behavior (Chiou et al., 2014). Another impact of implementing health promoting hospitals was a positive for organizational changes in capacity building for the HPH (Huang et al., 2016).

This research also shows that the HPH unit in the hospital has not conducted a program evaluation yet. Therefore, hospital staff do not know whether health promotion has effectively increased the knowledge of the patient or positively changed the health behavior of the target. Evaluation of health promotion is essential to collect the evidence of a program, identify aspects which should be improved, justify the use of resources and identify unexpected outcomes ( O’Connor-Fleming et al., 2006).

This research only focused on the management of the health promotion program and its performance in one hospital in Lamongan city, East Java. There is still a lack of HPH research conducted in Indonesia. Therefore, more research has to be done, particularly regarding the performance of the HPH based on WHO Standards, and its impact on the health of patient, community, organization, and staff.

\section{Conclusion}

Health promotion activities have been conducted by the HPH Unit of the hospital. The activities vary from inside the building, and include such indirect health education methods as pamphlets, posters, banners, and television to deliver health messages to the outside world, such as at patient gatherings, charity events, and home visits. Even though some activities have been conducted, there is still a problem in the management of the health promotion program in planning and evaluating activities. The manager of the hospital needs to increase the capacity of the HPH Unit members regarding the managerial aspect in implementing the health promotion program to be more effective. Besides that, there is a need to use the WHO standard in implementing the health promotion program in the hospital so that the targets of implementing of health promotion hospital are broader, including the patient, hospital staff, community, and organization.

\section{Acknowledgment}

We thank for hospital manager who has given permission for the researcher to conduct research in the hospital and staff who have greatly assisted during the research.

\section{References}

Potvin, L., \& Jones, C. M. (2011). Twenty-five years after the Ottawa Charter: the critical role of health promotion for public health. Canadian Journal of Public Health, 102(4), 244-248.

Charter O, \& Promotion H. (1986). Ottawa charter for health promotion. Health Promotion International, 1(4), 405.

Johnson A., \& Baum F. (2001) Health promoting hospitals: A typology of different organizational approaches to health promotion. Health Promot Int. 2001;16(3), 281-7.

Pelikan J. M., Krajic K., \& Dietscher C. The health promoting hospital (HPH): Concept and development. Patient Educ Couns, 45(4), 239-43.

Whitehead D. (2004). The European Health Promoting Hospitals (HPH) project. How far on? Health Promot Int, 19(2), 25967.

World Health Organization (2007). The International Network of Health Promoting Hospitals and Health Services: Integrating health promotion into hospitals and health services: concept, framework and organization. HPH: 
Integrating health promotion into hospitals and health services, 6-22. Retrieved from http://www.euro.who.int/_data/assets/pdf_file/0009/99801/E90777.pdf

Groene O. (2006) Implementing health promotion in hospitals: Manual and self-assessment forms. World Heal Organ Retrieved from: http://www.euro.who.int/pubrequest.

World Health Organization/Regional Office for Europe (2004). Standards for Health Promotion in Hospitals, 1-16.

Pelikan J. M., Gröne O., \& Svane J. K. (2011). The International HPH Network-A short history of two decades of development. Clin Heal Promot, 1(1), 32-6.

McHugh C., Robinson A., \& Chesters J. (2010). Health promoting health services: A review of the evidence. Health Promotion International, 25, 230-7.

Lee C. B., Chen M. S., \& Chu C. M. Y. (2013). The health promoting hospital movement in Taiwan: Recent development and gaps in workplace. Int J Public Health, 58(2), 313-7.

Yaghoubi M., \& Javadi M. (2013). Health promoting Hospitals in Iran: How it is. J Educ Health Promot 2(1), 41. Available from: http://www.jehp.net/text.asp?2013/2/1/41/115840

Larasanti A. (2017). Surabaya Implementation of Hospital Health Promotion in Rsu Haji Surabaya. J Promkes, 5(2), 117-27.

Nurdiana F. (2017). Universitas Airlangga Surabaya the Implementation of Health Promotion in Airlangga University Hospital Surabaya. J Promkes, 5(2), 217-31.

Chiou S. T., Chiang J. H., Huang N., \& Chien L. Y. (2014). Health behaviors and participation in health promotion activities among hospital staff: Which occupational group performs better? BMC Health Serv Res, 14(1).

Huang N., Chien L. Y., \& Chiou S. T. (2016). Advances in health promotion in Asia-Pacific: promoting health through hospitals. Glob Health Promot, 23, 26-34.

O’Connor-Fleming M., Parker E., Higgins H., \& Gould T. (2006). A framework for evaluating health promotion programs. Heal Promot J Aust, 17, 61-6. Retrieved from: http://www.publish.csiro.au/?paper=HE06061 